\title{
THE SIGNIFICANCE OF PSYCHICAL MONISM FOR PSYCHOLOGICAL THEORY
}

BY LEONARD THOMPSON TROLAND

Haroard University

The present period of controversy concerning the problem and scope of psychology appears to be characterized on the part of each of the disputing factions by an inability to perceive the facts and to conceive the ideas upon which the contentions of their opponents are based. This prevalent psychic blindness, however, is nowhere more clearly manifest than in the attitude of both introspectionist and behaviorist schools towards the doctrine known as psychical monism. This doctrine, which has appeared to the present writer since the very beginning of his studies in psychology to provide the simplest and most complete explanation of the psycho-physical relationship, has been expounded independently by several philosophers, or psychologists, since the time of Fechner [3], ${ }^{1}$ but has apparently found a place in only one ${ }^{2}$ out of the multitude of extant English textbooks of psychology. The cause of its failure to make an impression upon the psychological and philosophical public is not to be found in any lack of clearness in its conception or exposition on the part of its apostles. Clifford's [I] brief outline of the theory is a model of lucidity, while the elaborate discussions-by Strong [8] and by Heymans [3] leave scarcely any angle of the hypothesis unilluminated. Since a considerable group of the problems which constantly arise in modern psychological debate are reduced to objects of straw under the influence of this hypothesis, one might be tempted to attribute the failure of the theory to gain a wider acceptance to an intellectual incapacity on the part of contemporary psychological and philosophical thinkers.

1 Numbers in brackets refer to the bibliography.

stout, G. F., Manual of Psychology, London, 1907. 
However, if we wish to avoid this painful conclusion we may adopt the alternative of supposing that the advocates of psychical monism have failed in vociferousness; hence the present paper.

The essentials of the hypothesis in question are capable of being stated very simply and clearly, although the various conflicts which appear between its implications and the erroneous postulates of common sense soon lead to great confusion for the average thinker. For the psychical monist, consciousness, or the psychical, is identical with individual experience at any instant. Introspective psychology is merely the straightforward description by any individual of his own experience in its own terms without addition or subtraction from the given. No individual can describe in this manner any other individual's consciousness except in so far as the two consciousnesses overlap, which overlapping is assumed in fact never to occur. Physical science, including physiology, is distinguished from psychology both in regard to its method and its results. Now, physical science, although based upon individual immediate experience, is not concerned to obtain a mere description of such experience, but rather is seeking an account of certain supposed realities which lie outside of that closed experiential system and which are responsible for certain aspects of the latter. The doctrines of physics take the form of an interpretation rather than of a description of experience, this interpretation being couched exclusively in terms of concepts of mass, length and time (possibly with the addition of electric and magnetic dimensions) eliminating the myriads of other qualitative differentiz which are actually found in experience. The entire system of physical science, including physiology, is, therefore, in reality a metaphysical or a metempirical theory; the modern physicist's conception of the universe as a complicated dynamic mosaic of positive and negative electrons cannot be regarded with any reasonableness whatsoever as a direct deliverance of experience. It is nevertheless the ultimate or fundamental thing in physics, and its hypo- 
thetical character does not detract in the least from its stability in that realm. All biological and physiological concepts, including those of nervous operation or response which interest the psychologist, must ultimately be reduced to the centimeter-gram-second, electro-molecular constitution which is demanded by general physical theory. No matter how much the structures and processes of the nervous system may be integrated, they are ultimately nothing but a specific complicated and changing mosaic of electrical particles.

$\mathrm{U}_{\mathrm{p}}$ to fairly recent times it appeared possible for the physicist, if not for the critical philosopher, to regard the physical system as a description of something which actually existed, although it was not immediately found within any individual's experience. However, the developments of the relativity theory appear now quite to preclude this possibility. Formerly the physicist could believe that-although colors, tones, temperature qualities, etc., were merely psychological-space, mass and time were not only psychological but also externally real in nature. Relations which appear in Einstein's doctrine, however, make the nature of space, mass and time as dependent upon the observer as are the so-called secondary qualities. The physicist is still permitted to believe that his elaborate mathematical system is some sort of symbolic representation of an unknown external reality, but as to the qualitative nature of this reality he knows nothing. The path pursued by physics leads constantly away from the discovery of the intrinsic nature of the external universe.

In this situation, the psychical monist turns back to psychology, and in particular to physiological psychology, for an answer to the metaphysical question. He returns as a thinking individual to the classical laboratory psychological experiment in which he finds himself inferring in physical terms the operations of a certain nervous system, and at the same time believing that the words of the subject which he hears are actually indicative of the existence of 
a certain system of psychological entities-the other man's consciousness-which is associated with the nervous system in question. The detailed examination of many sets of data has led him to the general conclusion that this type of association consists in a point-to-point correspondence between psychical and physical terms and relations, a correspondence ordinarily called parallelism. The subject's consciousness is, from the experimenter's point of view, without any doubt an objective reality, but the nervous system and physical organism of the subject are pure hypotheses, the organism which the experimenter sees or feels being obviously nothing but an ephemeral complication of visual and tactual superficies. In the situation what is more obvious than the idea that the external reality corresponding to the physical hypothesis is nothing at all other than the subject's actual field of experience, or consciousness? This is the essence of the psychical monistic theory: The world of external reality is simply a complex system of psychical entities which are generally similar in character to the internal system which comprises any given observing or thinking individual. The entire system of physics is merely an unfinished product of the efforts of such an individual to arrive at a formulation of the abstract relations existing between the components of this external system. The physical scheme, in other words, is formally identical with the external psychical scheme, but its terms or qualities are absolutely different from those of the latter.

Following the indications of classical psychophysical data, we must suppose that the introspective consciousness of any subject in the psychological experiment finds physical representation, not in the sum total of his response processes or even in the totality of his nervous activities, but only in a very limited central or synaptic process occurring in his cerebral cortex. Since this elaborately hypothecated cerebral synergy is merely the symbolic representation in physical terms of the subject's actual consciousness, there is every reason why the two should have a parallelistic 
correspondence; but since the physical side of the correspondence is undoubtedly a fiction, the system is not dualistic. The only existential correspondence which is to be found is that which necessarily exists between the consciousness of the subject and the effects which this consciousness is producing in the second and separate consciousness of the experimenter.

The doctrine of psychical monism is immune to the attacks of Occam's razor, because it quite eliminates from the realm of reality one of the terms in the psychophysical dualism, viz, the physical term. It retains the abstract scheme of the physical system intact, but substitutes for space, mass and time (and electricity and magnetism) other terms of a more general psychical character. Space, mass and time are reduced to the level of specific psychological categories, thus falling from their exalted position as general dimensions of the universe. Space, mass and time are merely certain characteristics of perception in terms of which it has been found possible to work out a symbolic formulation of the system of external reality. But since the psychical monist still believes in an external universe equally complex with that which is pictured by the physicist, he must suppose that any introspective consciousness occupies a position in that general psychical system wholly analogous with that which is occupied by any focal, cortical, brain process in a complicated response activity. If the physical physiologist depicts a propagation of influences from stimulus through receptor and afferent path to the central synapses and out again efferently to effectors, then the psychical monist must suppose an entirely analogous series of processes taking place among organized psychical entities, and in which the introspective consciousness of any observer corresponds to the central, synaptic activities on the physical side. Utilizing a terminology introduced by the present writer, the introspective consciousness is the para-cerebrosis, but there must also be para-stimuli, para-receptor operations and paramotor results. The introspective system is thus an actually affected and effective term in a coherent dynamic or para- 
dynamic mechanism, which mechanism however is not made of matter but of the variegated stuff which constitutes consciousness.

Is this too difficult a doctrine for psychologists to grasp? I trust not, since once it has been clearly envisaged, nearly all of the dilemmas which are worrying modern psychological theorists and the realistic philosophers, disappear like darkness in the light. The old bugbear of interactionism versus parallelism is laid away in its grave. Psychical monism explains how the relation of seeming parallelism can arise in a system which is throughout interactionistic. Each introspective field of consciousness in the psychical monist's universe exercises an influence upon the course of events in the universe in conformity with exactly the same laws by which any other factor in this universe exerts an influence. There is no conflict with the principle of the conservation of energy, because this latter principle is purely physical and in order to gain significance for the external universe of consciousness, it must be transformed into a corresponding psychical or paraphysical law. This latter law is the actually effective principle, the physical principle being merely a symbolic translation of it. Just as the influences exerted by afferent nerve currents upon cortical synaptic processes and by the latter upon efferent nerve currents are presumably quite in harmony with the principle of energy conservation, so the influences exerted upon the introspective consciousness and those which emanate from the latter will be quite consistent with the principle of conservation of para-energy in the external psychic universe.

The hypothesis of psychical monism explains at once why the introspective consciousness is apparently determined by variables which are localized in a highly restricted region of the nervous system, in all probability one of the association areas of the cerebral cortex, and why this introspective consciousness has only a secondary determinative relationship with afferent and efferent nerve currents. If the introspective consciousness is, as it appears to be, a 
coherent group of psychical entities which is acted upon from the outside by other agencies and which in turn influences such other external realities, it should correspond to that portion of the physiological response mechanism which most integrally represents the same factors, sensory and motor, which find representation in consciousness. This condition is apparently satisfied by the focal brain process alone. Many modern semi-behavioristic writers are inclined to believe that consciousness depends simultaneously upon more than one stage in the response process, thus not being tied up exclusively with the central activity as is supposed by the classical specific energy theory. Kempf, ${ }^{1}$ for example, believes that the affective aspect of consciousness depends directly upon the functions of the autonomic nervous system, while the sensory aspects are determined by receptor processes, and these two aspects are welded together by the cortical activity. Dr. Head ${ }^{2}$ believes that the affective consciousness depends upon thalamic processes directly while the discriminative aspects of sensation are determined by the cerebral cortex. Dr. Kantor, ${ }^{3}$ Professor Holt ${ }^{4}$ and others are making strenuous efforts to correlate all of the categories of consciousness with efferent operations. A careful analysis of extant data, however, in the writer's opinion, shows quite clearly that these views are attributable to the urge for novelty or for objectification rather than to demands of data. The actual results of psychophysical observations favor what the present writer has called the monophasic cerebral theory of the determination of the introspective consciousness, and the laws which actually connect afferent or efferent processes with consciousness are explained in an entirely adequate way through the medium of purely physiological interrelations between central and peripheral factors in response.

While it cannot with fairness be claimed that the monophasic central theory has been absolutely proved by extant

1 Kempf, E. J. The Autonomic Functions and the Personality, (New York) 1921.

2 Head, Henry, 'Sensory Disturbances from Cerebral Lesions,' Brain, 34, 102-253.

- Kantor, J. R., 'Suggestions toward a Scientific Interpretation of Perception,' Psychol. Rev., 1920, 27, 191-216.

1 Holt, E. B. The Freudian Wish (1916). 
observations, it can be said without hesitation that this theory is the simplest explanation of all of the facts and that there are no facts as yet accessible which demand a polyphasic or a peripheral doctrine. On the whole, consciousness appears to be an afferent rather than an efferent product, so that the semi-behavioristic theories appear to be working quite in the wrong direction. This is not denying, of course, that under normal conditions the forms of consciousness are correlated with specific motor expressions, but this correlation appears to be merely an implication of the continuity of the normal response mechanism, the biological function of which in its entirety is, of course, to be found in action. For the psychical monist all of these correlations rest upon the fact that the physical scheme is merely an artificial, conceptual caricature of the introspective reality, the physical being thus an epiphenomenon of the psychical rather than vice versa.

From the point of view of psychical monism, the teachings of extreme behaviorists of the Watsonian type are outrageous in the extreme. The psychical monist would not for one moment deny the possibility of working out a physical explanation for any organic function, no matter how intricate. The physiologist does not need to introduce consciousness into his scheme at any point; as a physiologist, that is as a special kind of physicist, he has given up the study of consciousness at large and has restricted himself to the task of formulating the manifestations of the universe in physical terms. He must pick terms which will permit him to arrive at a closed system. From the standpoint of psychical monism the radical behaviorist, on the positive side of his activities, is simply a physiologist in a limited field. If behaviorism is the external study of the responses of organisms to stimuli, without reference to the detailed mechanism by which these responses are consummated, then behaviorism may be regarded as extra-cutaneous or superficial physiology. If, on the other hand, it is a study of the manner in which already complex physiological mechan- 
isms are fitted together to yield a biologically useful total reaction, then it is simply physiology of a gross rather than of a refined sort. The psychical monist can have no quarrel with either of these forms of physiology, although he may well doubt their self-sufficiency, or the ability of their exponents to maintain them as distinct subdivisions of physical science. When, however, the behaviorist says that he does not know what consciousness is, or denies that it exists, his expression seems to the psychical monist to be tantamount to a confession of complete ignorance or to a denial of the basis of all knowledge. Consciousness, for the psychical monist, is simply experience, and if the teachings of modern philosophy have any fruits at all, they certainly lead us to believe that all knowledge is derived from experience. If behaviorism is an empirical science it is based upon the observation of what the psychical monist designates as consciousness. This consciousness cannot, therefore, be unreal. Introspective psychology is merely a study of this consciousness, or its temporal variations which constitute experience, in and for itself without hypothesis. Behaviorism is a highly restricted interpretation of certain very limited aspects of the cansciousness in question, viz., certain, mainly visual, perceptions which are only obtained under the circumstances of physiological observation.

The latent intellectual utility of psychical monism for the psychologist is clearly demonstrated in the demands which appear in certain recent discussions. We may take as an example an admirable article by Professor Warren, ${ }^{1}$ with the general thesis of which the present writer is quite in agreement. Professor Warren insists upon the necessity of a monistic, or double-aspect, interpretation of the psychophysical nexus and yet appears to be quite unable to show how this monism is possible, since he admits that the phenomena of consciousness and those of the central neural processes, upon which he conceives consciousness to depend, are extremely different in character. He believes

I Warren, H. C., 'Psychology and the Central Nervous System,' Psycuor. Rev., I92I, 28, 249-269. 
that, in spite of this obvious discrepancy, it is still permissible-at least pragmatically-to identify them. To this belief the present writer is quite unable to subscribe, since it is clear to him that no two things which are in the slightest degree different in nature can be in the slightest degree identical. If consciousness and the brain process are one and the same thing, then one of the descriptions of this unitary being must be sadly in error, and clearly the only possibility of error lies in the physical system, since the introspective facts are immediately given, while the physical scheme is the result of a laborious and dangerous process of inference. Psychical monism announces blatantly that the entire physical scheme is grossly in error qualitatively, although it is quite correct in certain aspects of its mathematical form. This attitude permits a belief in monism which has no reservations and no unclearnesses. The physical scheme still exists in some sense, but only in the mind of the physicist when he happens to be thinking it, and the psychical monistic system at large makes it quite clear how he happens to think in this particular way when he does decide to think. There is actually-in Professor Warren's words-" a duplicate set of events" but one member of the set is of quite subsidiary and ephemeral importance in the universe as a whole. The psychical monistic theory, however, should interest Professor Warren in this connection since he says that the mutual relations of the members of this duplicate set of events "are not made clear in any statement with which [he] is familiar."

The present writer hopes in later papers to discuss in great detail many of the implications for philosophy and psychology of the psychical monistic, or-as he chooses to call it-the paraphysical, theory. In the meantime, however, he wishes to call attention of psychologists, and incidentally of philosophers, to the existence of this doctrine, which has already been expounded in great detail and with marvelous clearness by Heymans in his Einführung in die Metaphysik, as well as by a number of other writers. 


\section{Biblography}

צ. Cliffrord, W. R. Lectures and Essays (London), tgor, 2, I-73.

2. Barratt, M. A., Physical Metempiric, (London) 1883.

3. Fechner, G. T. Die Tagesansicht gegenüber der Nachtansicht. I994, 244-252, especially p. 244.

4. Hevmans, G. Einführung in die Metaphysik, Igor.

In Sachen der psychischen Monismus. Zeits. f. Prychol., 1912, 63, 241-285; 64, I-33.

Zur Parallelismusfrage. Zeits. f. Psychol., 1898, 17, 6z-105.

5. McDougn lu, Wrruma. Body and Mind (London), 1907.

6. Prince, Morton. The Nature of Mind and Human Automatism (Philadelphia), 1885.

How a Lesion in the Brain Results in that Disturbance of Consciousness known as Sensory Aphasia. Journ. of Neroous and Mental Diseases, 1885, 12, 255-268.

The Identification of Mind and Matter. Philos. Reo., 1904, 13, 444-45I.

Professor Strong on the Relation between the Mind and the Body. Psycroz. Rev., 1903, 10, 650-658.

7. Rogers, A. K. Review of Heymans' 'Einführung in die Metaphysik.' Phil. Reo, 1906, 15, 210-211.

8. Stout, G. F. Manual of Psychology (London), 1907, Chap. III.

9. Strong, C. A. Why the Mind has a Body (New York), 1903.

Dr. Morton Prince and Pansychism. Psychol. Rev., 1904, 11, 67-69.

Sur le Panpsychisme. Arch. de Psychol., 1905, 4, 145-154.

The Nature of Consciousness. Journ. of Phil., Psychol. and Sci. Methods, 1912, 9, 533-544; 561-573; 589-603.

Reply to Professor Bakewell. Phil. Reo., 13, 337-342.

10. Troland, L. T. Paraphysical Monism. Phil. Reo., 1918, 27, 39-62.

II. Turner, J. E. Dr. Strong's Panpsychic Theory of Consciousness and Perception. Journ. of Phil., Psychol. and Sci. Methods, 1919, 16, 428-433. 